\title{
Fracture behaviour of Cement Treated Sandy Clay
}

\author{
Kok Shien $\mathrm{Ng}^{1, \mathrm{a}}$, Yee Ming Chew ${ }^{2}$, and Sukri Nordin ${ }^{1}$ \\ ${ }^{1}$ Faculty of Civil Engineering, Universiti Teknologi MARA, Cawangan Pulau Pinang, 13500 Permatang Pauh, Pulau Pinang, Malaysia \\ ${ }^{2}$ Department of Mathematical Sciences and Computer, Universiti Teknologi MARA, Cawangan Pulau Pinang 13500 Permatang Pauh, \\ Pulau Pinang, Malaysia
}

\begin{abstract}
Addition of cement into soft soil has been proven to be useful in stabilizing the foundation. However, some failure cases are found related to this type of technique, especially involving the tensile failure of cement column as retaining structure. As we know, tensile strength of soil is important in controlling the cracking and tensile failure of many earth structures. This paper aims to investigate the fracture behaviour of cement treated sandy clay in terms of its compressive and tensile strength as well as its strain response under applied stress. Three laboratory testing namely the unconfined compression test (UCT), split tensile test (STT) and three-point bending test (TPBT) were conducted in this study. Cement content and curing period are the two main variables in the present study. The results of UCT showed the brittleness of the cement treated soil increased as the cement content and curing period increased. The unconfined compressive strength can be well correlated with the tensile strength obtained from STT and TPBT where the correlation factors were found to be 0.11 for both tests. Crushing mode is dominant in samples with high cement content and long curing period.
\end{abstract}

\section{Introduction}

Soft soil poses many construction problems such as large settlement, low bearing capacity and loss of stability, thus require special design considerations. One of the geotechnical solution to these problems is to treat the soil with cement by modifying the mechanical characteristics of soil and renders it with higher stiffness and strength. Successful of this ground improvement technique can be evidenced through many field applications [1-3].

Geotechnical properties of cement treated soil have been studied by many researchers [4-5]. However, most of the study focused on the compressive behaviour of the treated soil [6-7]. The tensile behaviour on the other hand has not been fully understood. The tensile behaviour is a very critical design criterion particularly for cement treated soil column used for earth retaining structure. Disregard of tensile forces has resulted in few failure cases of cement treated soil column wall [8].

The degree of improvement in mechanical properties is the major concern in assessing and controlling the quality of cement treated soil. The stability for shear failure of any geotechnical structure especially foundation and retaining structure requires proper consideration in the mobilised shear strength of the cemented treated soil. The shear strength of the treated soil can be estimated from unconfined compression strength, $q_{u}$ which can be easily determined from the unconfined compression test, UCT. Besides, consolidated isotropic undrained test (CIU), consolidated isotropic drained test (CID) and direct shear test are sometimes conducted too to estimate the shear strength of cement treated soil. Strength increment of treated soil is attributed to hydration and pozzolanic reactions. During the early stage of curing, hydration reaction is more controlling, and this has led to the formation of particle interlocking in the soil-cement skeleton. Meanwhile, the pozzolanic reaction is more significant at prolonged curing period and results in higher cohesion value [9].

The stiffness of cement treated soil, E in terms of initial Young's modulus, E0 and secant modulus of elasticity, E50 (at $50 \%$ of ultimate strength) is normally measured in unconfined compression test (UCT) even though the whole regime of stress-strain curve of cemented soil is nonlinear and decreases with strain increment [10]. Due to tedious work in obtaining the stiffness of treated soil, correlations have been made by researches to relate the stiffness, $\mathrm{E}$ with the unconfined compression strength. However, wide range of results were obtained varies from $\mathrm{E}=80 \mathrm{qu}$ to $\mathrm{E}=1000 \mathrm{qu}[5,11$, $12,13]$. The difference of results is basically due to different soil types in testing, varies of water-cement ratio used, and testing methods.

Although cement addition to soft soil helps to increase the strength and compressibility, it has changed 'tension such as tensile cracking is often encountered in many earth structures namely slopes, dams, hydraulic barriers, embankments. Even though cement addition has also increase the tensile strength of the treated soil, it does not stop the tensile cracks from happening

\footnotetext{
${ }^{\mathrm{a}}$ Corresponding author: ngkokshien@uitm.edu.my
} 
especially when subjected to desiccation, differential settlement or large external loads. The tensile strength of the cemented soil, $\sigma_{t}$ can be determined from uniaxial tension test, also known as direct tensile test. The tensile strength is often correlated to the unconfined compression strength where $\sigma_{t} \approx 0.05 q_{u}$ to $0.3 q_{u}$ [14-16]. The correlation should be used with care, as the empirical relationship differed from soil to soil. Like unconfined compression test, strain softening behaviour is observed in cemented soil where the material is not able to sustain the maximum load under further straining. Alternatively, tensile strength can be obtained using indirect tensile test such as split tensile test (named also as Brazilian test), STT which is simple in sample preparation and easy to conduct. However, the major drawback of using STT is that there is no strain measurement and therefore the stress-strain response of the cement treated soil is unclear.

Flexural strength, obt obtained from bending test is commonly used in measuring the tensile strength of concrete which show quasi-brittle behaviour as in cement treated soil. Flexural behaviour of cement treated soil has been investigated by only few researchers [1719]. Using three-point bending test (TPBT), Nakikawa and Koseki [20] investigated the post-peak behaviour of cement treated sand using energy balance approach. Although the tensile toughness is an essential characteristic of fracture mechanic in cement treated soil, it has never been explicitly considered in the geotechnical design. This is because its importance has not been well understood and lack of quantifying method [8].

The tensile behaviour of cement treated soil has not gain enough attention compared to the compressive behaviour. This paper aims to evaluate the fracture mechanism of cement treated sandy clay and to establish the relationship of compressive strength and tensile strength of the treated soil. Split tensile strength was used to obtain the tensile strength while three-point bending test was used to obtain the tensile toughness of the cement treated soil.

\section{Methodology}

\subsection{Sample preparations}

Sandy clay at depth about $1.5 \mathrm{~m}$ was collected from an excavation project in Bukit Mertajam, Pulau Pinang. The physical properties of the sample are shown in the Table. 1. Ordinary Portland cement Type 1 obtained from local cement factory was used in the study. Table 2 summarizes the chemical composition and physical properties of the cement. Cement contents, $A_{w}$ of $20 \%$ and $40 \%$ were selected in this study which correspond to water cement ratio, $w / c$ of 0.75 and 0.375 respectively. These values are reasonably representative of the cement content used in treating the soft soil. Unconfined compression strength and tensile strength were obtained from samples prepare with natural moisture content, $m=$ $15 \%$ compacted to the bulk density of $1.9 \mathrm{Mg} / \mathrm{m}^{3}$.
Table 1. Physical properties of soil.

\begin{tabular}{lc}
\hline Properties & Value \\
\hline Grain size distribution $(\%)$ & $(\%)$ \\
Clay & 39 \\
Silt & 12 \\
Sand & 33 \\
Gravel & 16 \\
Liquid limit & 88 \\
Plastic limit & 38 \\
Plasticity index $(\%)$ & 50 \\
Specific gravity $(\%)$ & 2.59 \\
Bulk density $\left(\mathrm{Mg} / \mathrm{m}^{3}\right)$ & 1.89 \\
Dry density $\left(\mathrm{Mg} / \mathrm{m}^{3}\right)$ & 1.58 \\
Natural moisture content $(\%)$ & 15 \\
Soil classification & Sandy clay of very high \\
& plasticity \\
\hline
\end{tabular}

Table 2. Chemical and physical properties of cement used in this study.

\begin{tabular}{cc}
\hline Chemical composition (\%) & \\
\hline $\mathrm{SiO}_{2}$ & 19.0 \\
$\mathrm{Al}_{2} \mathrm{O}_{3}$ & 5.4 \\
$\mathrm{Fe}_{2} \mathrm{O}_{3}$ & 2.7 \\
$\mathrm{CaO}$ & 60.3 \\
$\mathrm{MgO}$ & 1.7 \\
$\mathrm{SO}_{3}$ & 2.9 \\
$\mathrm{~K}_{2} \mathrm{O}$ & 0.1 \\
$\mathrm{Na}_{2} \mathrm{O}$ & 0.0 \\
$\mathrm{LOI}$ & 5.3 \\
\hline Physical properties & \\
\hline $\mathrm{S} . \mathrm{G}$ & 3.1 \\
Fineness $\left(\mathrm{m}^{2} / \mathrm{kg}\right)$ & 365 \\
\hline
\end{tabular}

\subsection{Unconfined compression test}

Unconfined compression test, UCT was conducted to determine the unconfined compression strength of treated and untreated samples according to BS 1377-7 (1990). A cylindrical PVC split-mold with inner diameter of $50 \mathrm{~mm}$ and height of $100 \mathrm{~mm}$ was used for UCT specimen. Specimens are prepared for 7, 14 and 28 days of curing for cement treated samples. The strain rate was set at $1.55 \mathrm{~mm} / \mathrm{min}$. The loading was stopped when the recorded load reduced or remained constant at $10 \%$ of the maximum load.

\subsection{Split tension test}

Splitting tensile test, STT was performed with a diametral compression testing machine to determine the indirect tensile strength. The test is performed as specified in European standard EN 13286-42. $50 \mathrm{~mm} \mathrm{x}$ $50 \mathrm{~mm}$ cylindrical specimens were used in the study. The loading rate was kept at $0.5 \mathrm{~mm} / \mathrm{min}$. Fracture crack initiates perpendicular to the direction of the applied load once maximum tensile stress is applied and finally separates into two halves. By assuming the treated soil 
to be a linear elastic material, the tensile strength of the sample is calculated by,

$$
\sigma_{s t}=-\frac{2 P}{\pi t r}
$$

where $P$ is the ultimate load at failure, $t$ is the sample length and $r$ is the diameter of the sample.

\subsection{Three-point bending test}

The three-point bending test (TPBT) was conducted on cement treated soil beam specimens. The ASTM D1609 was used as reference. A flexural beam test setup was developed with soil beam dimensions of $150 \mathrm{~mm}$ in length, $40 \mathrm{~mm}$ in width, and $40 \mathrm{~mm}$ in depth as shown in Figure 1. The specimens were vertically loaded at the middle of two simple supports until failure happened. The loading rate of $0.1 \mathrm{~mm} / \mathrm{min}$ was applied and the test stopped when the 10 $-20 \%$ of strain was achieved. The flexural strength, $\sigma_{b t}$ can be calculated as:

$$
\sigma_{b t}=-\frac{P L d}{8 I}
$$

where $L$ is the span length, $d$ is the beam depth and $I$ is the moment of inertia for the beam section.

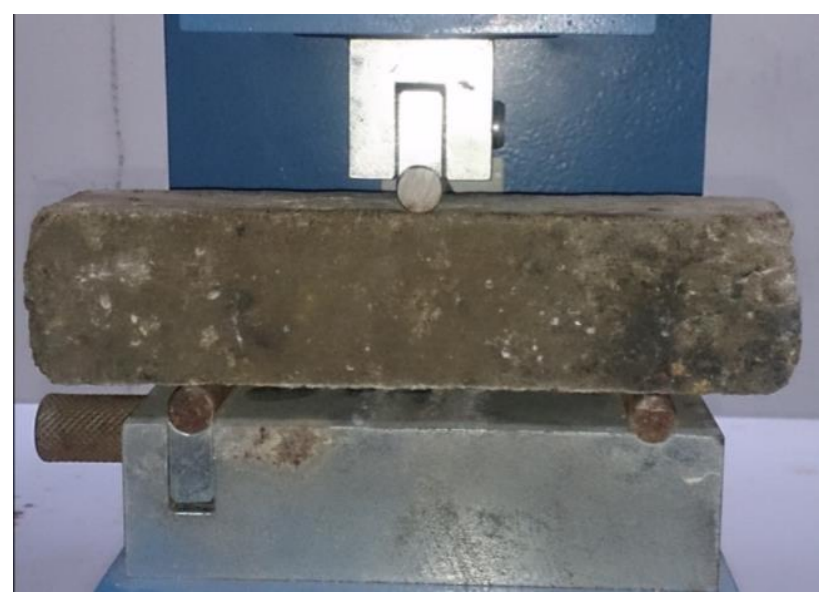

Figure 1. Three-point bending test set up.

\section{Results and discussion}

\subsection{Compressive behaviour of cement treated soil}

The compressive behaviour of the cemented soil is evaluated with UCT. Figure 2 shows the stress-strain curves for the both the treated and untreated soils. The stress-strain curves for the cement treated samples are generally found to surge up to the peak values and then decline rapidly to small values upon further straining. Cement treated soils appear to be more brittle compared to the untreated soil and the ductility decreases with the increase of cement content and curing period. Cemented soils behave more like a quasi-brittle material at shorter curing period as the softening part in the stress-strain curves is gentler and less abrupt compared to the longer curing period. Untreated soil tends to fail in shear while the fracture behaviour in cement treated soils are more complex with the either shear, splitting, crushing or the combination of these as shown in Figure 3. With higher cement content, i.e. $A_{w}=40 \%$, cured in 28 days, compressive crushing failure is more dominant. Similar failure modes were also reported by Saw [8] for Singapore marine clay treated with cement.

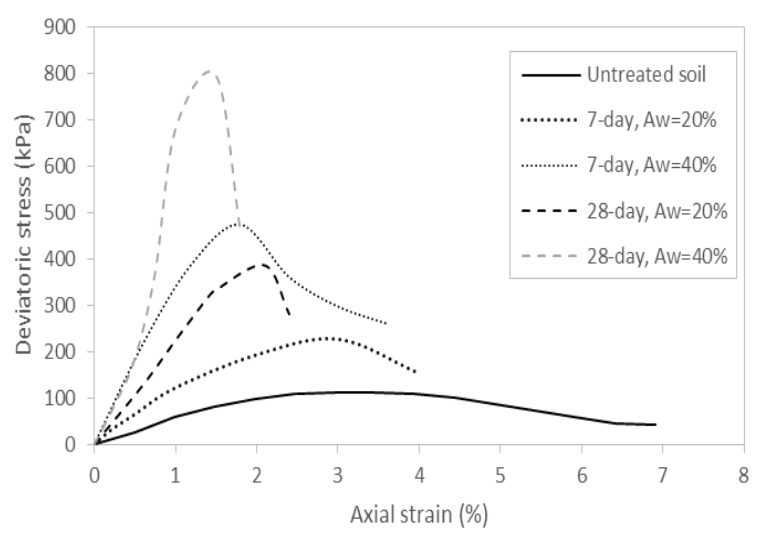

Figure 2. Stress-strain response under uniaxial load.

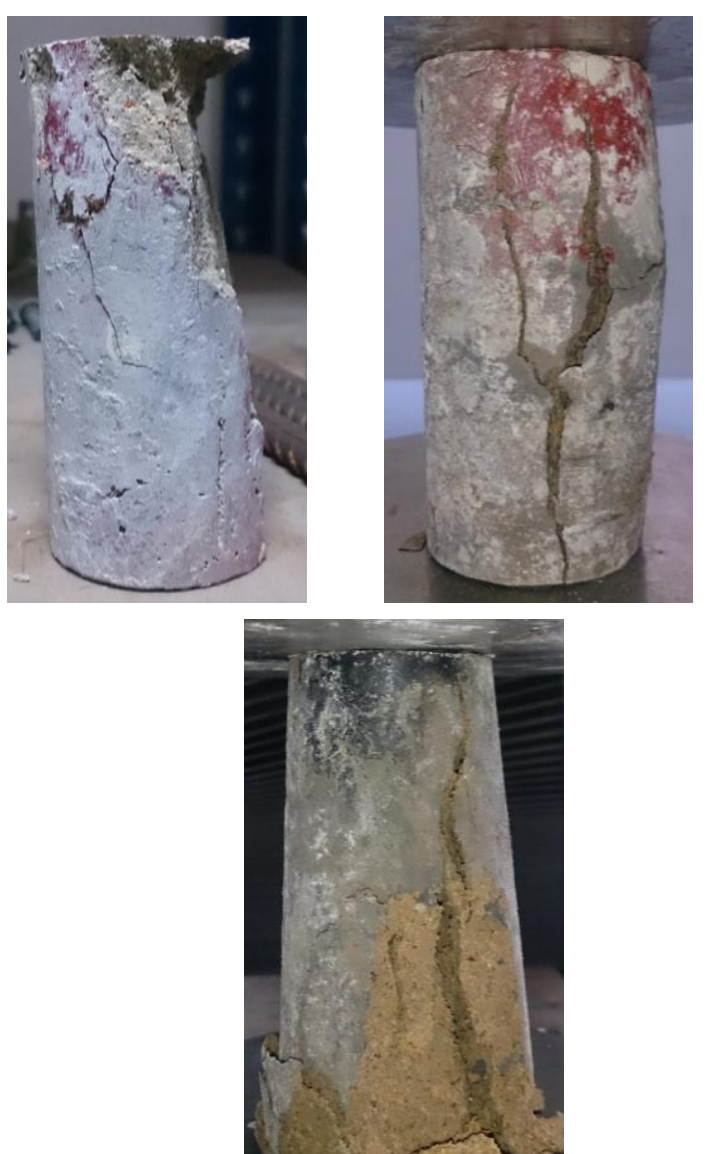

Figure 3. Stress-strain response under uniaxial load Fracture behaviour in cemented samples (a) 7-day, $A_{w}=20 \%$, (b) 7-day, $A_{w}=40$, (c) 28-day, $A_{w}=40 \%$.

The increase in compressive strength with higher cement content is due to the effectiveness of cement hydration and pozzolanic reaction, capable of binding together the clay particles and thus resulting in a newly 
bonded and stronger soil matrix. Due to the longer lasting of pozzolanic effect, the strength of the cemented soil is expected to increase with time. Figure 4 shows the unconfined compressive strengths $\left(q_{u}\right)$ of the cementtreated soil of different cement contents and different curing days. It is found that the influence of cement content is more pronounced than the curing period. At curing period of 28 days, the unconfined compressive strengths increase by threefold and sevenfold for samples treated with cement content of $20 \%$ and $40 \%$ respectively compared to the untreated soil with $q_{u}=110$ $\mathrm{kPa}$. The strength increment observed in this study is consistent with that reported by others [2,9]. In this study, the correlations obtained for secant modulus and unconfined compressive strength of cemented soil are $E_{50}=100-166 q_{u}$ (where $E_{50}=$ Secant modulus of elasticity at $50 \%$ of ultimate strength) which is quite similar to the results obtained by Lorenzo and Bergado [21] for Bangkok clay.

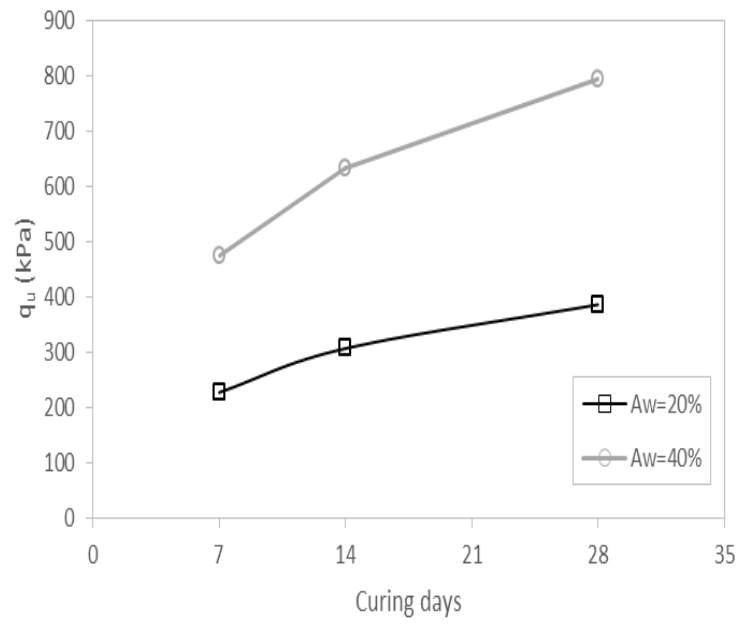

Figure 4. Unconfined compressive strength versus curing period for two different cement contents.

\subsection{Tensile behaviour of cement treated soil}

The results of split tension test are presented in Figure 5. Like the results of unconfined compressive strength, the split tensile strength, $\sigma_{s t}$, of cement-treated sandy clay increases with increase in cement content and curing period. The split fracture was observed during the testing as shown in Figure 6. Figure 7 shows the relationship between split tensile strength and unconfined compressive strength for cement-treated soil used in the present study. Good correlation can be obtained between these two parameters:

$$
\sigma_{b t}=0.11 q_{u}
$$

The correlation between unconfined compressive strength and split tensile strength in the present study lies within the ranges reported in other studies. Clough et al. [22] reported the ratio of tensile to compressive strength of 0.1 for cemented sand. While Porbaha et al. [16] gave a value between 0.1 and 0.15 for peat stabilized with cement. Namikawa and Koseki [19] showed the ratio of 0.1 to 0.3 for cement treated Toyoura sand.

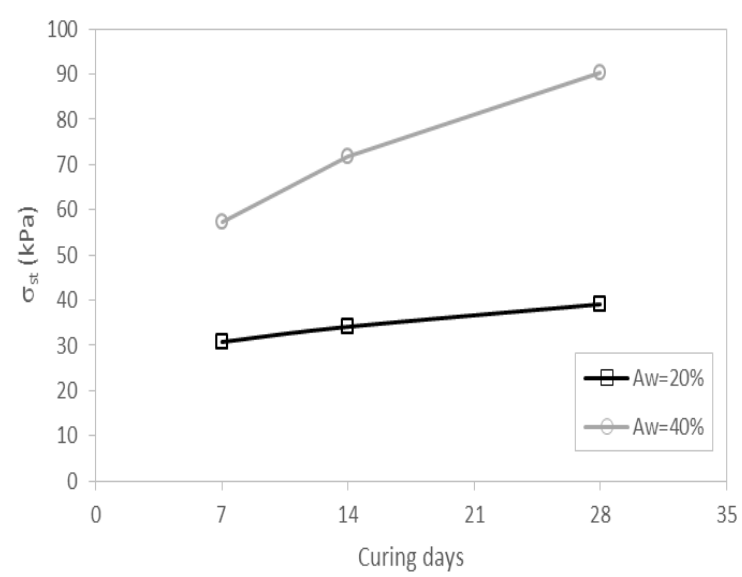

Figure 5. Split tensile strength versus curing period for two different cement contents

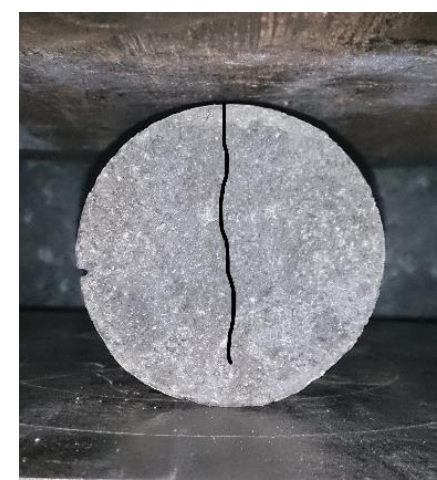

Figure 6. Front view of specimen during maximum loading applied.

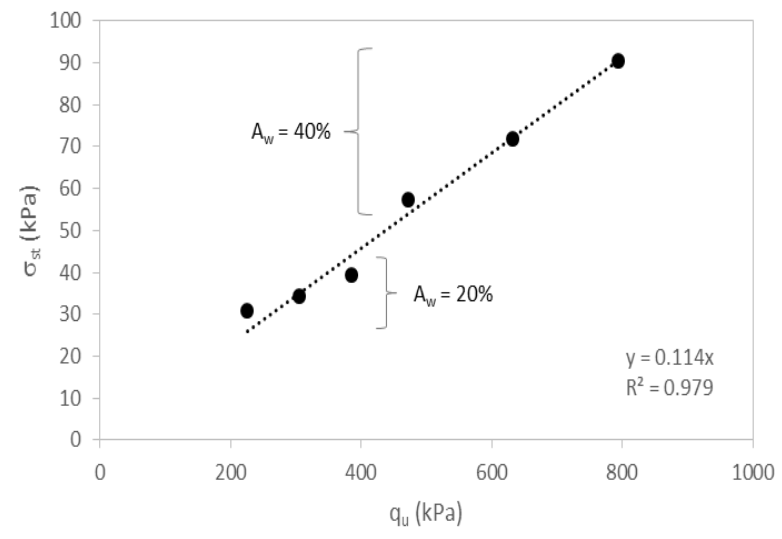

Figure 7. Relationship between unconfined compressive strength and split tensile strength.

Figure 8 shows the results obtained from TPBT. Good linear relationship can be obtained for tensile strength and unconfined compressive strength with the correlation ratio of 0.11 similar to that obtained from STT. Single flexural crack is observed in the beam as shown in Figure 9.

\section{Conclusion}

This paper examined the fracture behaviour of cement treated sandy clay in both compression and tension. Cement content of $20 \%$ and $40 \%$ was used in this study. The test program involved three types of tests namely UCT, SST and TPBT. Under compression loading as in 
$\mathrm{UCT}$, the stress increased rapidly to a maximum value and then decreased sharply to a small value upon further straining. For material with low cement content and short curing period, the admixture becomes quasi-brittle. Fracture modes of shear, splitting, crushing or the combination of these were observed in the samples. For higher cement content of $40 \%$ cured in 28 days, compressive crushing was dominant. Correlation ratio of secant modulus to unconfined compressive strength is found to be between 100 and 166. In both STT and TPBT, tensile strength increased with cement content and curing period. The tensile strength can be well correlated with the unconfined compressive strength, with $\sigma_{s t}=0.11 q_{u}$.

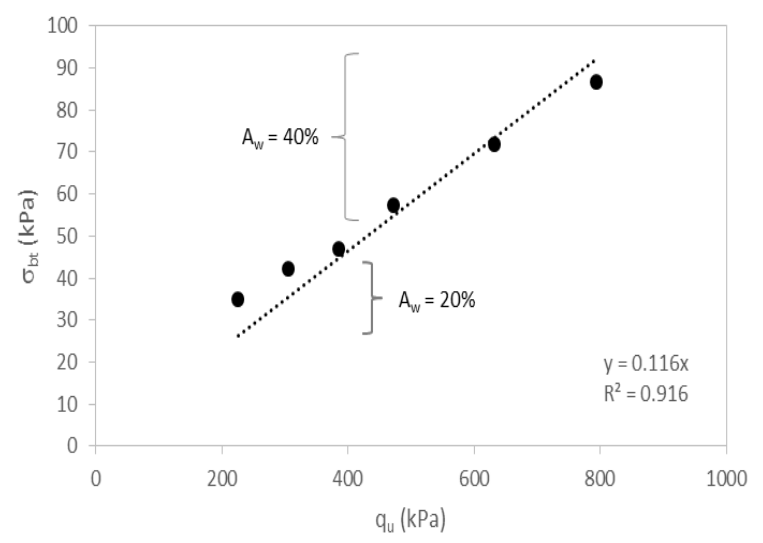

Figure 8. Relationship between unconfined compressive strength and flexural strength.

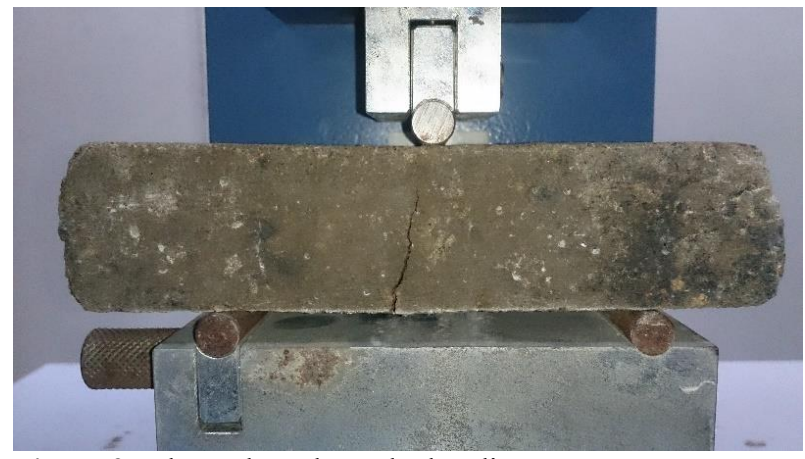

Figure 9. Flexural cracks under bending stress.

\section{Acknowledgments}

The authors would like to thank Universiti Teknologi MARA, Cawangan Pulau Pinang of supplying the research materials and providing research facilities for the current research.

\section{References}

1. H. Hayashi, J.I. Nishikawa, K. Ohishi, M. Terashi, Grouting and ground treatment, 598-609 (2003)

2. K. Uddin, A.S. Balasubramaniam, D.T. Bergado, Geotech. Eng. 28, 89-119 (1997)

3. V.P. Faro, N.C. Consoli, F. Schnaid, A. Thomé, L. da Silva Lopes, J. Geotech. Geoenviron. 141(6), 06015003 (2015)

4. S.H. Chew, A.H.M. Kamruzzaman, F.H. Lee, J. Geotech. Geoenviron. 130(7), 696-706 (2004)

5. G.A. Lorenzo, D.T. Bergado, J. Geotech. Geoenviron. 130(10), 1042-1050 (2004)

6. F. Sariosseiri, B. Muhunthan, Eng. Geol. 104(1), 119-125 (2009)

7. L.S. Ho, K. Nakarai, Y. Ogawa, T. Sasaki, M. Morioka, Constr. Build. Mater. 134, 703-712. (2017)

8. A.L. Saw, Characterisation and Modelling of Cement-Treated Soil Column used as Earth Retaining Structure (Doctoral dissertation), National University of Singapore (2014)

9. A.H.M. Kamruzzaman, Physico-chemical and engineering behaviour of cement treated Singapore marine clay (Doctoral dissertation), National University of Singapore (2002)

10. T.S. Tan, T.L. Goh, K.Y. Yong, Geotech. Test. J. 25(4), 422-433 (2002)

11. T. Kawasaki, Seminar on Soil Improvement and Construction Techniques in Soft Ground Singapore, 17-38 (1984)

12. M. Futaki, K. Nakano, Y. Hagino, Grouting and Deep Mixing Conference, Tokyo , 481-484 (1996)

13. F.H. Lee, Y. Lee, S.H. Chew, K.Y. Yong, J. Geotech Geoenviron. 131(2), 178-186. (2005)

14. Y.S. Fang, J.J. Liao, T.K. Lin, Q. J. Eng. Geol. Hydroge. 27(3), 257-265. (1994)

15. S. Saitoh, Y. Suzuki, S. Nishioka, Grouting and Deep Mixing, Balkema, 557-562. (1996)

16. A. Porbaha, S. Shibuya, T. Kishida, Proceedings of the Institution of Civil Engineers-Ground Improvement, 4(3), 91-110 (2000)

17. L. Raad, Behavior of Cement-Treated Soils in Flexure(No. 1190) (1988)

18. T. Namikawa, J. Koseki, Soils and Foundations 47(4), 657-674 (2007)

19. V. Anggraini, A. Asadi, A. Syamsir, B.B. Huat, Measurement 111, 158-166 (2017)

20. T. Namikawa, J. Koseki, Soils and Foundations 46(4), 491-504 (2006)

21. G.A. Lorenzo, D.T. Bergado, J. Mater. Civil Eng.ASCE 18(2), 161-174 (2006)

22. G.W. Clough, N. Sitar, R.C. Bachus, N.S. Rad, J. of Geotech. Eng. Divison 107(6), 799-817 (1981) 